\title{
Hormonal Regulation of Circadian Pacemaker in Ovary and Uterus
}

\author{
Masa-aki Hattori \\ Kyushu University, Fukuoka \\ Japan
}

\section{Introduction}

Ovarian folliculogenesis is characterized by drastic proliferation and differentiation of granulosa cells and theca cells. Although it is well accepted that gonadotropins and ovarian steroids play the central roles in follicular development by controlling follicular microenvironments, intrafollicular substances including growth factors and cytokines are known to function as modulators of ovarian follicular growth and development. Differentiation of granulosa cells involves follicle-stimulating hormone (FSH)-induced maturation of immature cells into mature cells. The expressions of related genes are rigidly controlled until ovulation, and then granulosa and theca cells are finally differentiated into luteal cells, which produce progesterone. On the other hand, the uterus is closely synchronized to the ovary: increasing ovarian steroids regulate the uterus as one of the principal targets to prepare for embryo implantation following fertilization. In the uterus composed of heterogeneous cell types including luminal and glandular epithelial cells, stroma cells, and muscle layers-estradiol stimulates the proliferation of epithelial cells, whereas progesterone inhibits estradiol-induced hyperplasia of the epithelial compartments (Carson et al., 2000). In rodents, the endometrial stroma cells undergo proliferation and decidualization in response to ovarian steroids and embryo implantation at the early stage of pregnancy (Clarke \& Sutherland, 1990; Dey et al., 2004). Thus, cellular functions in the ovary and uterus are accompanied by cyclic changes of cell proliferation, differentiation and apoptosis. The circadian clock system may contribute to the progress of follicular development, luteinization and luteolysis, and steroid hormone-induced proliferation and differentiation of uterine cells through fluctuating hormones. Recently, there is a growing body of evidence that circadian clock genes are expressed in reproductive tissues including the ovary and uterus (Johnson et al., 2005; Nakamura et al., 2005; Fahrenkrug et al., 2006; Dolatshad et al., 2006; Karman \& Tischkau, 2006; He et al., 2007a, 2007b, 2007c; Nakao et al., 2007; Hirata et al., 2009; Sellix \& Menaker, 2010; Uchikawa et al., 2011). Many regulatory elements are located at the upstream of clock genes, such as steroid hormone response element half-sites and the adenosine $3^{\prime}, 5^{\prime}$-cyclic monophosphate (cAMP) response element site as well as E-box and D-box elements. The mammalian circadian system is composed of three components: input pathways, central pacemaker, and output pathways. The input pathways transmit environmental signals to the central pacemaker, which coordinates the external signals with the central endogenous rhythm of the body by neural, hormonal and behavioural cues (Reppert \& Weaver, 2001; Schibler \& Sassone-Corsi, 2002; Yamamoto et al., 
2004; Duguay \& Cermakian, 2009). At the molecular level, the circadian systems through expression of clock genes generate circadian changes in cell functions via identified transcriptional and posttranscriptional regulatory processes. The CLOCK-BMAL1 heterodimers formed by the bHLH-PAS-activating clock-controlled genes, including Per, CKIE, Clock, Bmal1, and Cry, bind to the canonical E-box element of these promoters and initiate the transcription activities of these genes. The PER and CRY proteins, in turn, form multimeric complexes and feed back to repress the transactivation by CLOCK/BMAL1 in the nucleus (Ueda et al., 2005). The peripheral oscillators, synchronized by the central clock, control the expression of downstream clock-controlled genes in tissue-specific relationships. Here, the hormonal regulation of the circadian clock system in ovarian and uterine cells is reviewed and studied in rats. The study indicated that the circadian pacemaker is altered in ovarian and uterine cells during cellular differentiation, which is induced by hormonal stimulation.

\section{Real-time monitoring of circadian oscillation in primary cultured cells}

Cell lines such as fibroblasts also display several oscillations of the clock gene expression when treated with dexamethasone, serum shock or other stimuli (Balsalobre et al., 2000a, $2000 \mathrm{~b}$ ). To precisely analyze the circadian clock system, a real-time system for monitoring gene expression has been employed using transgenic rats constructed with mouse Per2

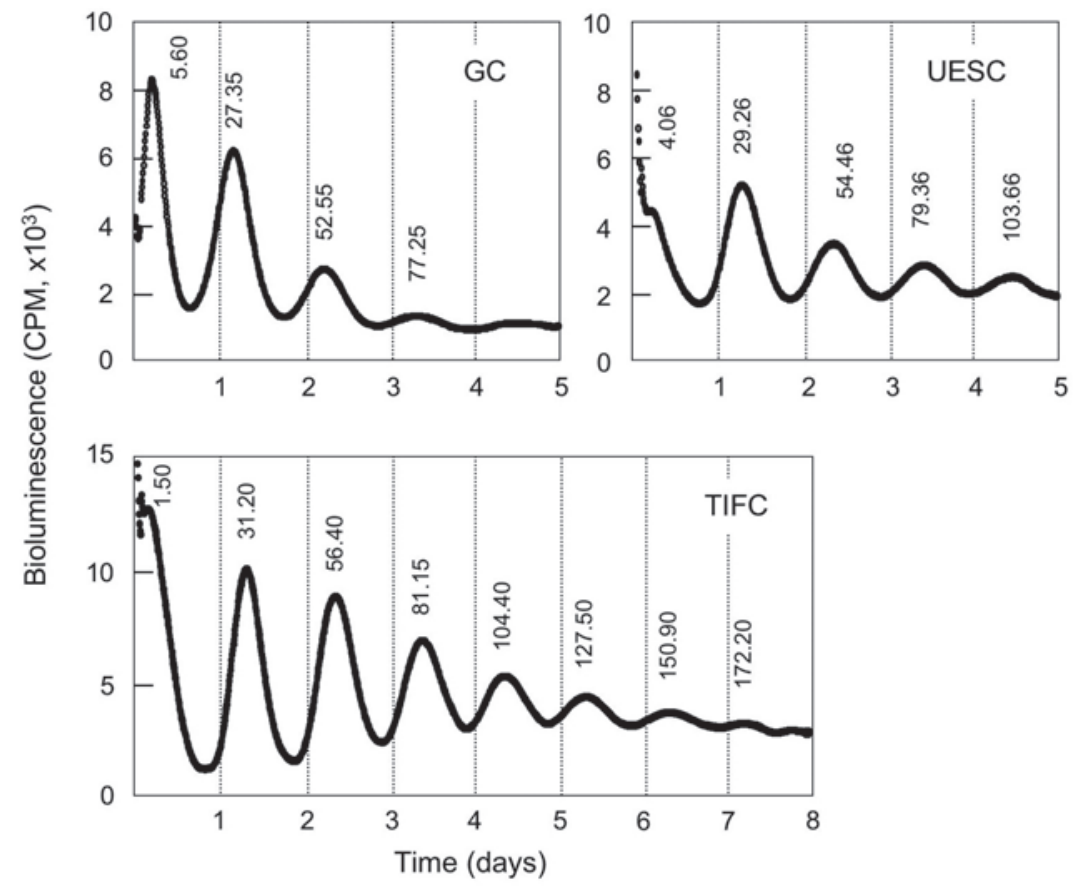

Fig. 1. Profiles of circadian Per2-dLuc oscillations in ovarian granulosa cells (GC), uterine endometrial stroma cells (UESC) and testicular interstitial fibroblast-like cells (TIFC) treated with dexamethasone. The values are the peak times (hours) in each oscillation. 
promoter-destabilized luciferase (Per2-dLuc) reporter gene (Ueda et al., 2002). Transgenic rats were maintained under 12-h L and 12-h D (zeitgeber time, ZT0; 08:00 h light on; ZT12: 20:00 $\mathrm{h}$ light off). Three cell types were prepared from the ovary, uterus and testis: i.e., ovarian granulosa cells, uterine endometrial stroma cells and testicular interstitial fibroblast-like cells. These cell types exhibited several oscillations after exposure to dexamethasone, but the number of oscillations for each cell type was distinct (Fig. 1). The times of the second oscillation were $27.35 \mathrm{~h}$ in the granulosa cells, $29.26 \mathrm{~h}$ in the stroma cells, and $31.20 \mathrm{~h}$ in the testicular interstitial fibroblast-like cells, but the cycle times were similar ( $24 \mathrm{~h})$.

\section{Circadian rhythm in ovarian cells under hormonal stimulation}

Several laboratories have reported the expression of clock genes in the ovarian follicles and corpora lutea in vivo, but their conclusions are mostly conflicting. Studies on the circadian clock in the Drosophila ovary suggested that period and timeless were constantly expressed in the follicular cells (Beaver et al., 2003). The diurnal rhythms of Per1 and Per2 expression were reported in the corpora lutea of rat ovaries (Fahrenkrug et al., 2006). In contrast, Bmal1 and Per2 were rhythmically expressed in the rat ovarian follicles but not in the corpora lutea (Karman \& Tischka, 2006). In the current study, preantral and antral ovarian follicles of immature transgenic rats were primed with diethylstilbestrol and equine chorionic gonadotropin (eCG), respectively (Fig. 2, A), to obtain granulosa cells. In both cell types, an oscillation of Per 2 promoter activity was observed at approximately $4 \mathrm{~h}$ after exposure to dexamethasone. While oscillation was induced in both, the oscillatory patterns of two cell types were different. In the granulosa cells from preantral follicles only one weak oscillation was induced, subsequent to the initial oscillation, which occurred at approximately $24 \mathrm{~h}$ (Fig. 2, B \& C). Conversely, a few robust oscillations were detected in the granulosa cells from antral follicles, albeit with a continuous decreasing of amplitude (He et al., 2007a). FSH was also effective at inducing the oscillation seen at approximately $24 \mathrm{~h}$ (Fig. 2, C). This distinctness may be related to each cellular physiology. Granulosa cells spontaneously undergo cellular apoptosis in vitro (Tilly et al., 1992). However, it is unlikely that the cell death caused the cessation of oscillation in the granulosa cells after only one cycle, as $90 \%$ of the cells were still viable, and additional oscillation could be evoked by replacement with fresh medium or stimulation with forskolin (Fig. 2, B). This finding suggests that, in vivo, the circadian clockwork is somewhat influenced in follicular granulosa cells during the process of cell differentiation or maturation. The clock system was also analyzed in the luteal cells that were prepared from ovaries of immature rats primed by eCG and human chorionic gonadotropin (hCG). The luteal cells exhibited several circadian oscillations with high amplitude after exposure to forskolin or dexamethasone (Fig. 2, D). However, the oscillation shifted forward approximately $3 \mathrm{~h}$ when the cells were treated with forskolin. The profiles of oscillation for dexamethasone and forskolin treatments were distinct, although the cycle times were the same, approximately $24 \mathrm{~h}$. The first oscillation was found at 3-5 h after the initiation of monitoring, although the time was dependent upon the stimulant. LH was also effective at inducing circadian oscillation in luteal cells (Fig. 2, D).

\section{Circadian rhythm in uterine cells under hormonal stimulation}

Ovarian steroids regulate the proliferation and differentiation of uterine endometrial stroma cells (Carson et al., 2000). In addition, in the rat Per 2 gene, many estrogen response element (ERE) half-sites and progesterone response element (PRE) half-sites are located at the 
A
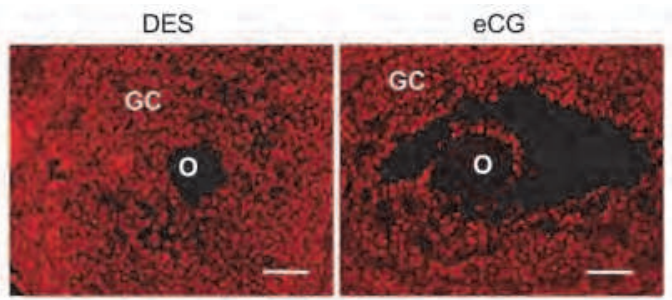

B

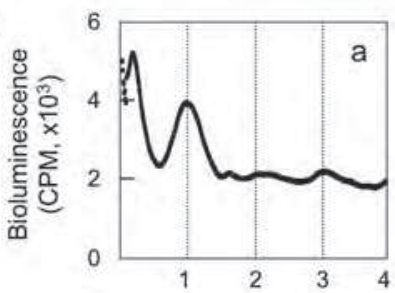

C

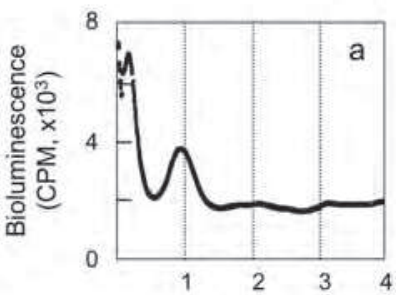

D

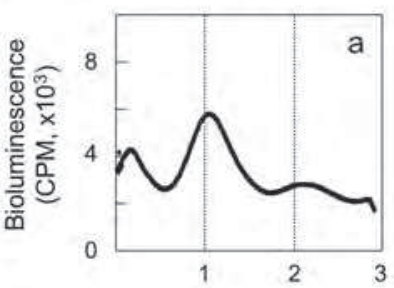

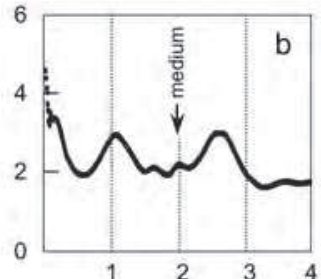


Fig. 2. Circadian oscillation of Per2- $d$ Luc in granulosa cells and luteal cells. A, Observation of the PER2 protein in preantral (DES injection for 3 days) and antral (eCG injection) follicles of ovaries by fluorescent immunohistochemistry. GC, granulosa cells; O, oocytes. Scale bar, 50 $\mu \mathrm{m}$. B, The granulosa cells isolated from preantral follicles were cultured for $48 \mathrm{~h}$ with medium containing $5 \%$ FBS. The oscillation of Per2- $d L u c$ was induced after exposure to dexamethasone (a). Culture medium containing with (c) or without (b) $10 \mu \mathrm{M}$ forskolin was replaced at $48 \mathrm{~h}$ after the initiation of bioluminescent monitoring. C, Granulosa cells from preantral (a) and antral follicles $(b, c)$ were cultured as described above and treated with dexamethasone $(a, b)$ for $2 \mathrm{~h}$, and then subjected to real-time monitoring of bioluminescence. FSH was contained in the culture medium during monitoring (c). D, Luteal cells prepared from luteinized ovaries of rats primed by eCG and hCG were cultured as described above and treated with forskolin (a) or dexamethasone (b) for $2 \mathrm{~h}$, and then subjected to real-time monitoring of bioluminescence. LH was contained in the culture medium during monitoring (c). 
upstream of the transcription start site. These sites may contribute to the expression of the Per2 gene by ovarian steroid hormones. It is well known that eCG injection causes the formation of antral follicles in ovaries that produce estradiol, and hCG injection thereafter results in luteinization of ovarian follicles that produce large amounts of progesterone. The large amounts of estradiol and progesterone promote proliferation and differentiation in the uterus. The stroma cells proliferate in the eCG-primed rat uterus, compared to those in the hCG-primed rat uterus. The stroma cells were treated with dexamethasone or forskolin. In the stroma cells prepared from intact immature rats, cyclic Per2 oscillation was observed after exposure to dexamethasone or forskolin (Fig 3, a \& e) (Hirata et al., 2009). This suggests that the glucocorticoid response element (GRE) and cAMP response element (CRE) sites in the rat Per 2 promoter are operative and transactivate the transcription of the Per 2 gene (Travnickova-Bendova et al., 2002; Yamamoto et al., 2004). Although the second oscillation in the stroma cells was delayed compared to that in the ovarian cells (He et al., 2007c), the circadian oscillator was operative with approximately $24 \mathrm{~h}$ per cycle. In contrast, the stroma cells from eCG-primed rats exhibited an irregular rhythm of Per2 oscillation with a smaller trough (Fig. 3, b \& f). Disrupted oscillation was also observed in the cells 2 days after hCG priming subsequent to eCG priming (Fig. 3, c \& g). However, in the cells of rats 4 days after hCG priming subsequent to eCG priming, the disrupted oscillation recovered to a rhythmic
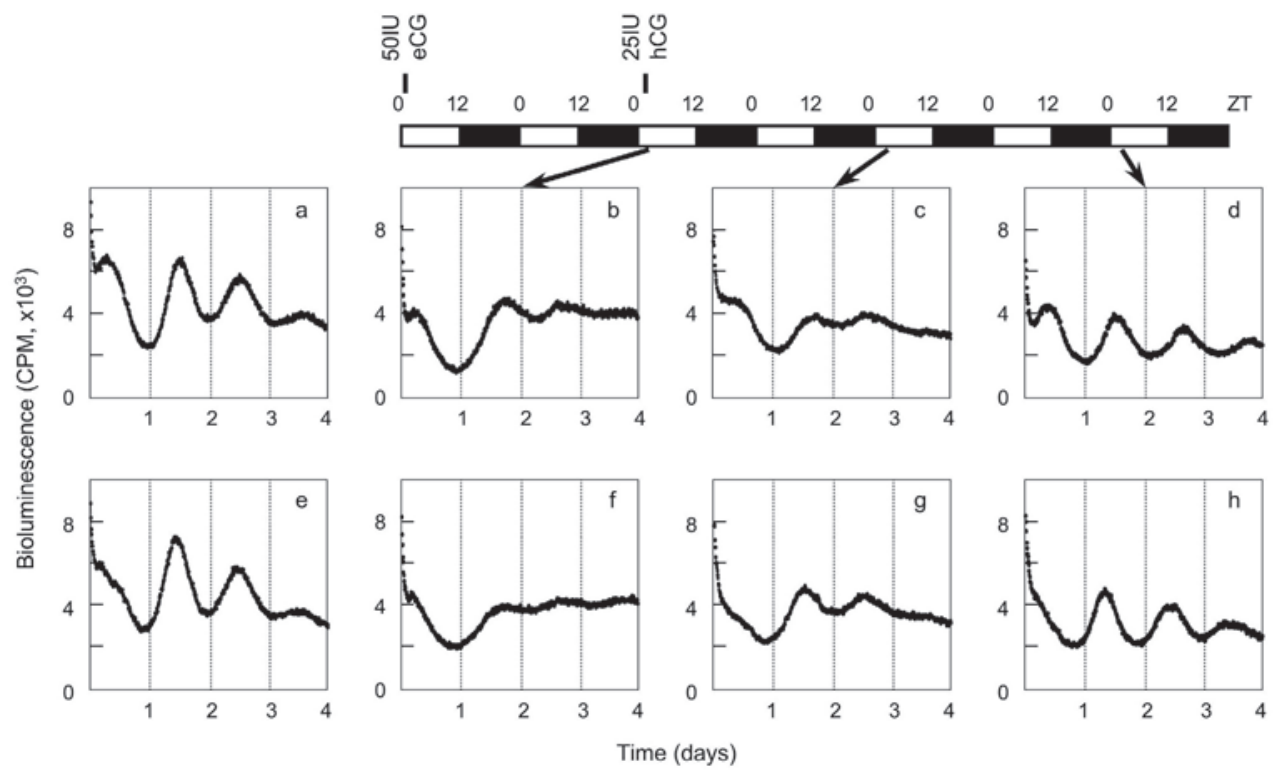

Fig. 3. Circadian oscillation of Per2- $d L u c$ in uterine endometrial stroma cells prepared from intact or gonadotropin-primed rats. Immature rats were primed with or without 25IU hCG following 50IU eCG, and the stroma cells isolated were cultured for $48 \mathrm{~h}$ with medium containing 10\% FBS. The cells were treated with dexamethasone (a-d) or forskolin (e-h), and then subjected to real-time monitoring of bioluminescence. a, e: stroma cells from intact rats; b, f: cells from rats 2 days after priming with eCG; c, g: cells from rats 2 days after priming with hCG subsequent to eCG priming; $d$, h: cells from rats 4 days priming with hCG subsequent to eCG priming. 
pattern with a 24-h cycle, similar to those observed in intact immature rats (Fig. 3, d \& h). Chronic treatment with estradiol is known to disrupt the circadian rhythms of Per1 and Per2 expression in the liver, kidney and uterus (Nakamura et al., 2005). Furthermore, the phase of the estrous cycle has a profound effect on the oscillation of the PER2 protein within the brain (Perrin et al., 2006). The circadian oscillator may be operative in the stroma cells after progesterone administration, through the transcriptional and feedback loops of the clock system. Consequently, it is possible that estradiol does not induce rhythmic Per 2 oscillation, whereas progesterone promotes the rhythmic pattern.

\section{Expression of Per1 gene in uterine cells by ovarian steroids}

The uterus undergoes profound remodelling, implicating cyclic proliferation, differentiation and differential gene expression dependent on the levels of circulating ovarian steroids. Recent studies have demonstrated that circadian clock genes are rhythmically expressed in the uterus (Nakamura et al., 2005; Dolatshad et al., 2006). Expression of Per1 mRNA was analyzed by in situ hybridization in different compartments of the uterus at ZT 0 and ZT 8 (He et al., 2007c). The expression could be readily detected in both the endometrium and myometrium at ZT 0 and ZT 8 (Fig. 4). Strong signals were observed in the luminal epithelium and glandular epithelium, as compared to that in the stromal cell layer. The staining intensity of Per1 mRNA was approximately two-fold higher at ZT 8 than at ZT 0 in the stroma, luminal epithelium and myometrium compartments. It is noted that the staining signal did not apparently change at ZT 0 and ZT 8 in the glandular epithelium compartment. This suggests the lack of rhythmical clockwork in the control of uterine glandular physiology. The effects of estradiol and progesterone on the expression of Per1

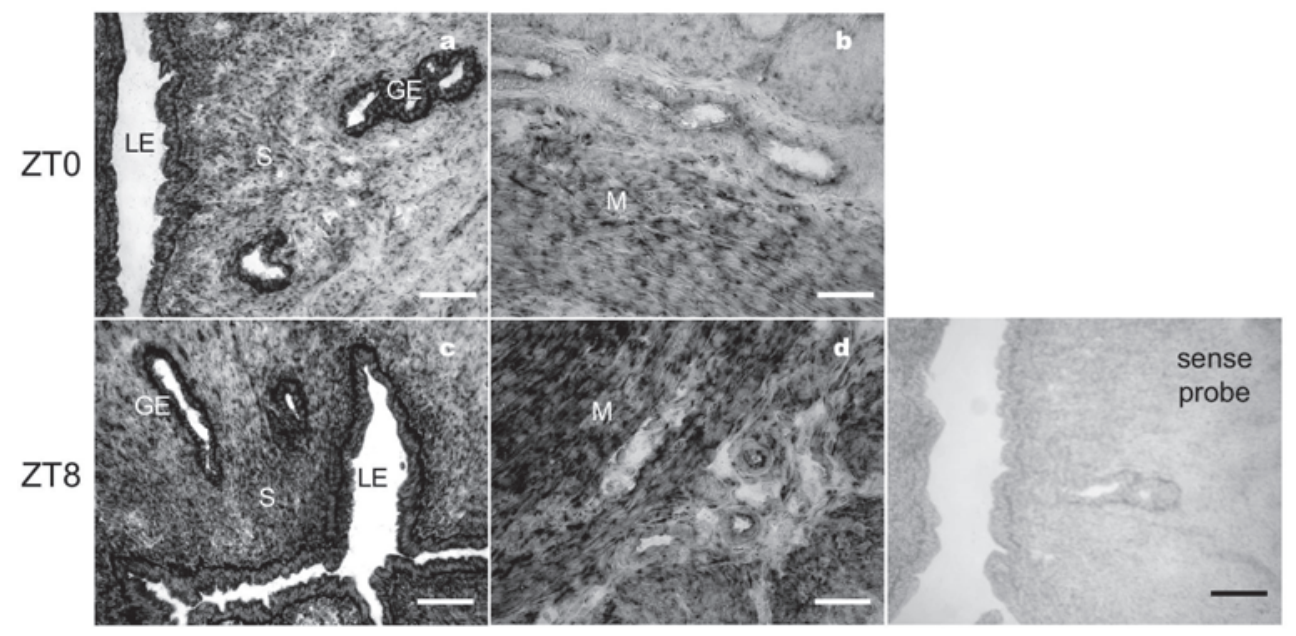

Fig. 4. Representative photomicrographs of in situ hybridization analyses for Per1 mRNA in diestrous uteri. The uterine samples were obtained at ZT0 (a, b) and ZT8 (c, d). Dark shades show the staining of Per1 mRNA. No signal was obtained in the uteri stained with a sense probe. S, stroma; LE, luminal epithelium; GE, glandular epithelium; M, myometrium. Scale bars, $100 \mu \mathrm{m}$. 
mRNA were evaluated in the uteri of ovariectomied rats. All the uteri were collected at ZT 0 after a single injection of ovarian steroids. In situ hybridization analysis revealed that the estradiol-primed uteri exhibited much stronger staining in the luminal epithelium, glandular epithelium and myometrium compartments (Fig. 5). However, the staining signal was weak in the stroma compartment. In addition, treatment with an ER antagonist (ICI182,780) caused a decrease of the staining intensity of Per1 mRNA in all examined compartments (Fig. 6). This indicates that the Per1 expression is at least partly through the

A

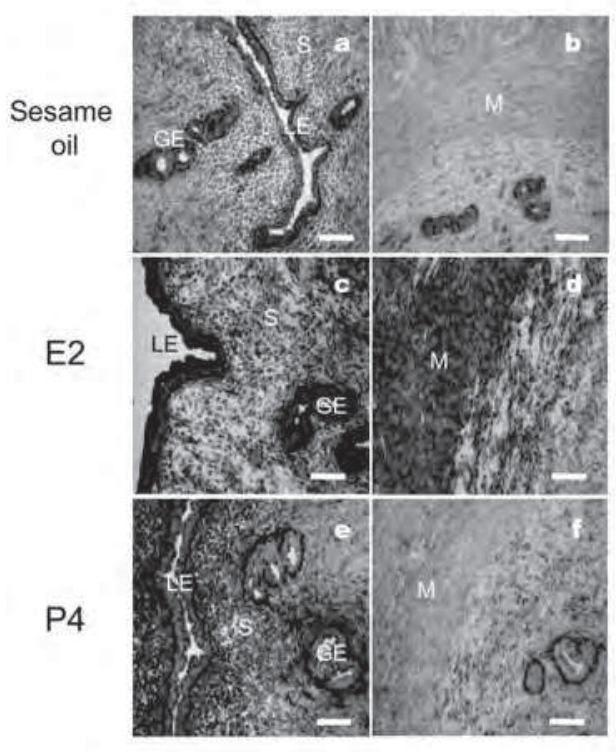

B
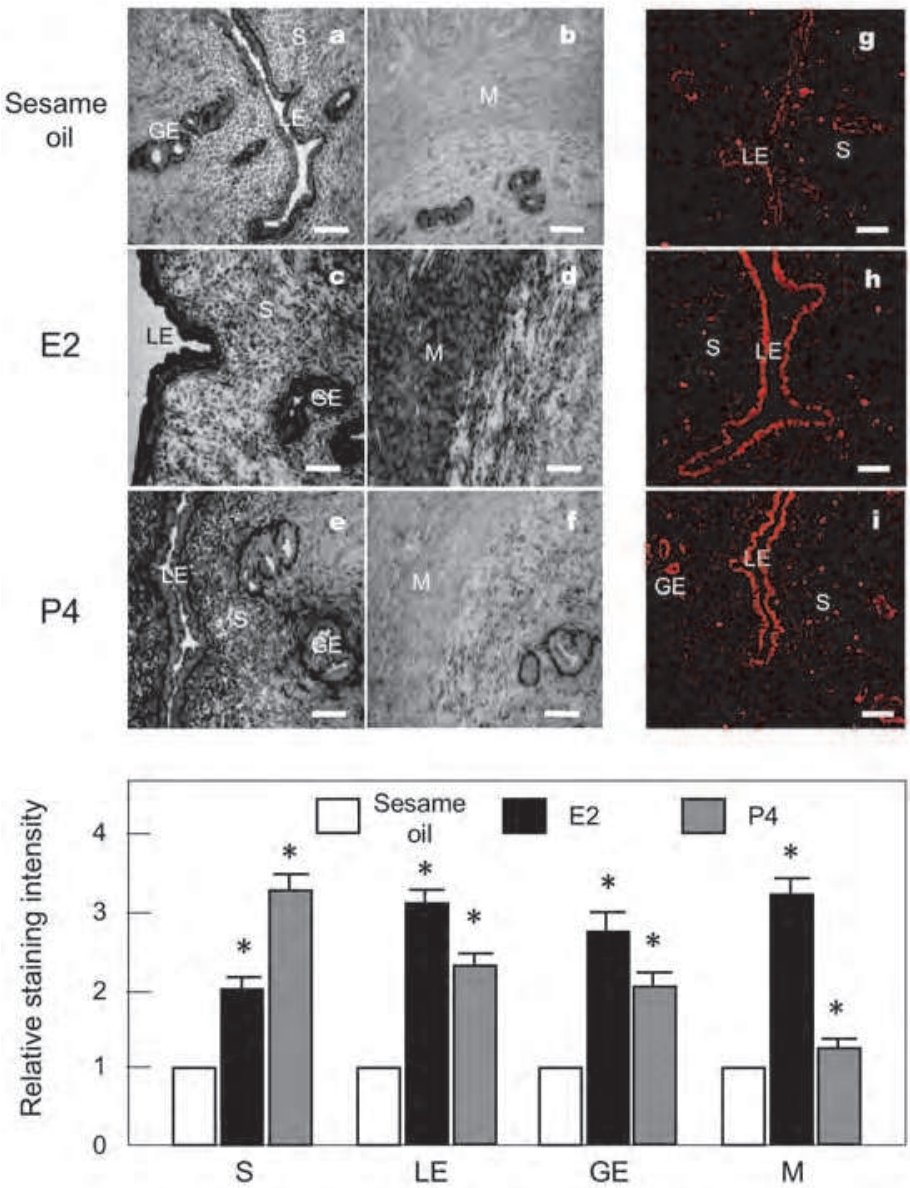

Fig. 5. Representative photomicrographs of in situ hybridization analyses for Per1 mRNA (A) and immunofluorescent analyses for PER1 protein (B) in the uteri treated with estradiol (E2) or progesterone (P4). At ZT0, the OVX rats were injected subcutaneously with $100 \mu \mathrm{l}$ sesame oil-containing vehicle $(\mathrm{a}, \mathrm{b}, \mathrm{g}), 50 \mu \mathrm{g} / \mathrm{kg}$ E2 (c, d, h), or $10 \mathrm{mg} / \mathrm{kg}$ P4 (e, f, i), and uteri were removed after $24 \mathrm{~h}$. The relative changes of Per $1 \mathrm{mRNA}$ staining are presented as means \pm SEM of three independent sections. S, stroma; LE, luminal epithelium; GE, glandular epithelium; M, myometrium. Scale bars, $100 \mu \mathrm{m}$. 


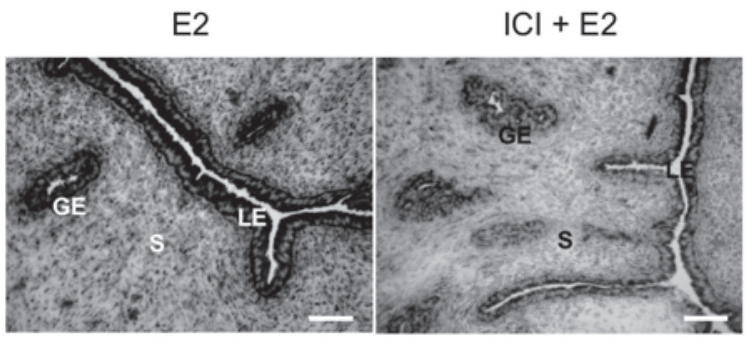

P4

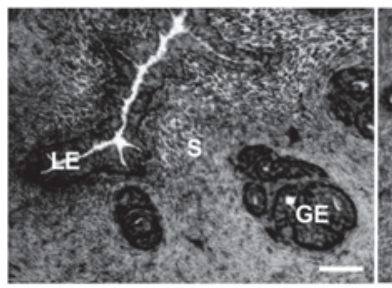

$R U+P 4$

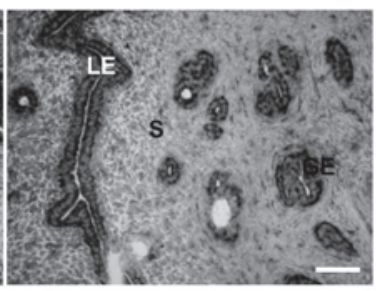

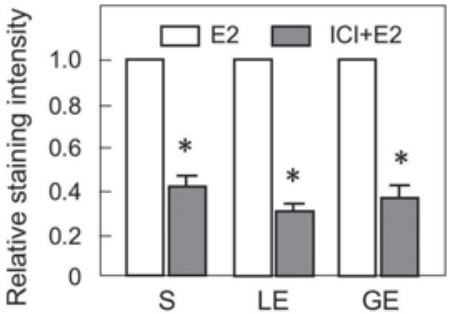

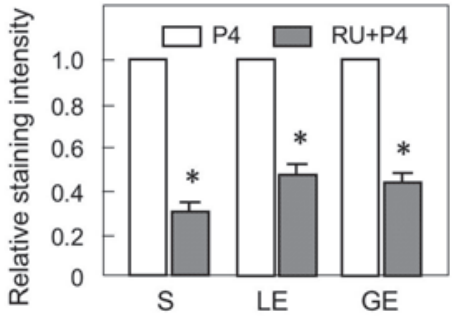

Fig. 6. Representative photomicrographs of in situ hybridization analyses for Per 1 mRNA in the uteri treated with estradiol (E2), E2 + ICI182780, progesterone (P4), or P4 + RU486. At ZT0, the OVX rats were injected subcutaneously with $100 \mu$ l sesame oil-containing vehicle, 3 $\mathrm{mg} / \mathrm{kg}$ ICI182780, or $30 \mathrm{mg} / \mathrm{kg}$ RU486, after $2 \mathrm{~h}$, followed by injection with $50 \mu \mathrm{g} / \mathrm{kg}$ E2 or $10 \mathrm{mg} / \mathrm{kg}$ P4. The uteri were collected at ZT0 the following day. The relative changes of Per1 mRNA staining are presented as means \pm SEM of three independent sections. S, stroma; LE, luminal epithelium; GE, glandular epithelium; M, myometrium. Scale bars, $100 \mu \mathrm{m}$.

*Statistical significance vs. the control $(p<0.05)$.

ER-mediated pathway. The differences in Per1 mRNA expression among the compartments might result from differential expression of ER. Actually, the ER mRNA or protein is expressed at higher levels in the luminal epithelium, glandular epithelium and myometrium compartments than in the stroma at $24 \mathrm{~h}$ after estradiol administration (Nephew et al., 2000). This pattern of ER distribution, to some extent supports the current Per1 mRNA expression profile in the uterus in response to estradiol. On the other hand, progesterone administration resulted in intense staining in the stroma, luminal epithelium and glandular epithelium compartments, but not in the myometrium compartment (Fig. 5). Treatment with a PR antagonist (RU486) remarkably inhibited Per1 mRNA expression in the stroma and glandular epithelium compartments (Fig. 6). These observations indicate that ER and PR might mediate estradiol- and progesterone-regulated Per1 expression in the uterus, respectively. Immunofluorescent staining for the PER1 protein was performed in estradioland progesterone-administered uteri. In the control uteri, relatively stronger staining was observed in the luminal epithelium and glandular epithelium compartments, with weak staining in the stroma. With estradiol treatment, the PER1 protein was more intensively expressed in the stroma, luminal epithelium and glandular epithelium compartments. Treatment with progesterone also resulted in stronger immunostaining of PER1 in the stroma, luminal epithelium and glandular epithelium compartments. Immunohistochemical observations of PER1 expression in response to ovarian steroids were similar to the results 
revealed by in situ hybridization. The activated expression of Per1 by ovarian steroids might result from the direct binding of receptors for estrogen and progesterone to some potential elements (ERE, PRE) in the Per 1 promoter. There is no consensus ERE (5'GGTCANNNTGACC-3') site, but some ERE half-sites are located in the 5' flanking region of the Per1 promoter (Nakamura et al. 2005).

\section{Expression and distribution of the PER2 protein in the uterus during gestation}

In studies on the expression pattern of the Per 2 mRNA in the uterus of estrous mice, a robust daily variation was reported with a peak around early dark periods (Dolatshad et al., 2006). However, little is known about whether the circadian clockwork is modulated during gestation. In rodents and humans, uterine endometrial stroma cells undergo proliferation and differentiation into decidual cells, ultimately leading to the formation of the placenta. We previously described that the rhythmic Per2- $d L u c$ oscillation is not observed in the stroma cells undergoing decidualization induced by medroxyprogesterone acetate plus N6, 2-O-dibutyryl adenosine 3':5'-cyclic monophosphate (He et al., 2007b). Stroma cells isolated from pregnant rats on day 4.50 of gestation are proliferative in culture. Cells isolated from the transgenic rats were employed to analyze circadian oscillation on day 4.50 (ZT 4) and day 6.50 (ZT 4). On day 4.50, treatment of the stroma cells with dexamethasone caused the generation of circadian Per2-dLuc oscillation. This indicates that GREs in the rat Per2 promoter are functional and transactivate the transcription of the Per2 gene (Travnickova-Bendova et al., 2002; Yamamoto et al., 2004; He et al., 2007b). Although the second oscillation in the stroma cells is delayed compared with that of ovarian cells (He et al., 2007b), the circadian oscillation was obvious, with approximately $24 \mathrm{~h}$ per cycle at least during the stage of implantation. In contrast, the circadian oscillation was attenuated in the decidualizing cells only 2 days after implantation. However, the times of each oscillation in the stroma cells on day 4.50 and day 6.50 of gestation were mostly identical. The expression and distribution of the PER2 protein were investigated by fluorescent immunohistochemistry in different compartments of the uteri (day 4.5) at ZT 4 and ZT12 (Uchikawa et al., 2011). A strong immunostaining signal was detected in the luminal epithelium, as compared to that in the stroma cell layer (Fig. 7), which was similar to the distribution of the PER1 protein. The cytoplasm of the luminal epithelium especially exhibited a strong signal at both ZT4 and ZT12. This suggests a continuous expression of the PER2 protein. On the other hand, in the stromal cell layer, immunostaining signals were observed in both the nuclei and cytoplasms at ZT4, whereas signals were observed predominantly in the nuclei at ZT12. Fluorescent immunohistochemical studies may support the circadian rhythm of the PER2 protein at least in the stroma cell layer. In contrast to the implantation stage, no significant rhythm of the PER2 protein was found during the decidualization stage (day 6.5 to day 6.8). Fluorescent immunohistochemistry revealed a strong signal in the cytoplasm of the luminal epithelium at both ZT4 and ZT12 (Fig. 7). As compared to the implantation stage, immunostaining signals were observed predominantly in the nuclei of stroma cell layers at both ZT4 and ZT12.

\section{Circadian rhythm in uterine endometrial stroma cells during gestation}

The uterine endometrial stroma cells prepared from several stages of gestation (pregnancy days 2.5, 4.5 and 6.5; P2.5, P4.5, P6.5, respectively) exhibited different responses to 


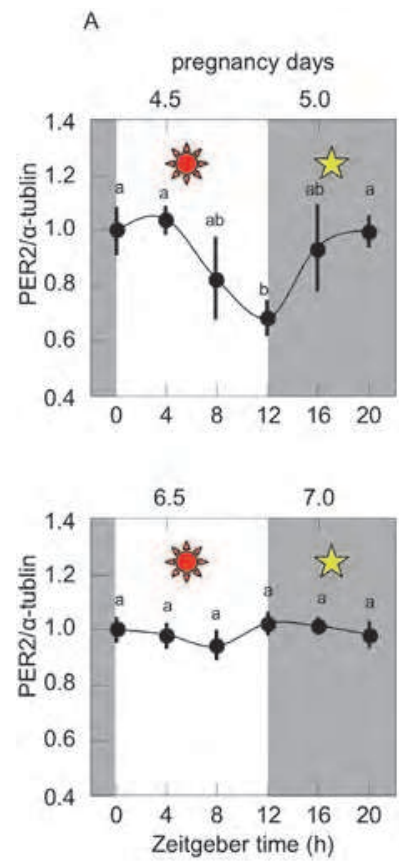

B

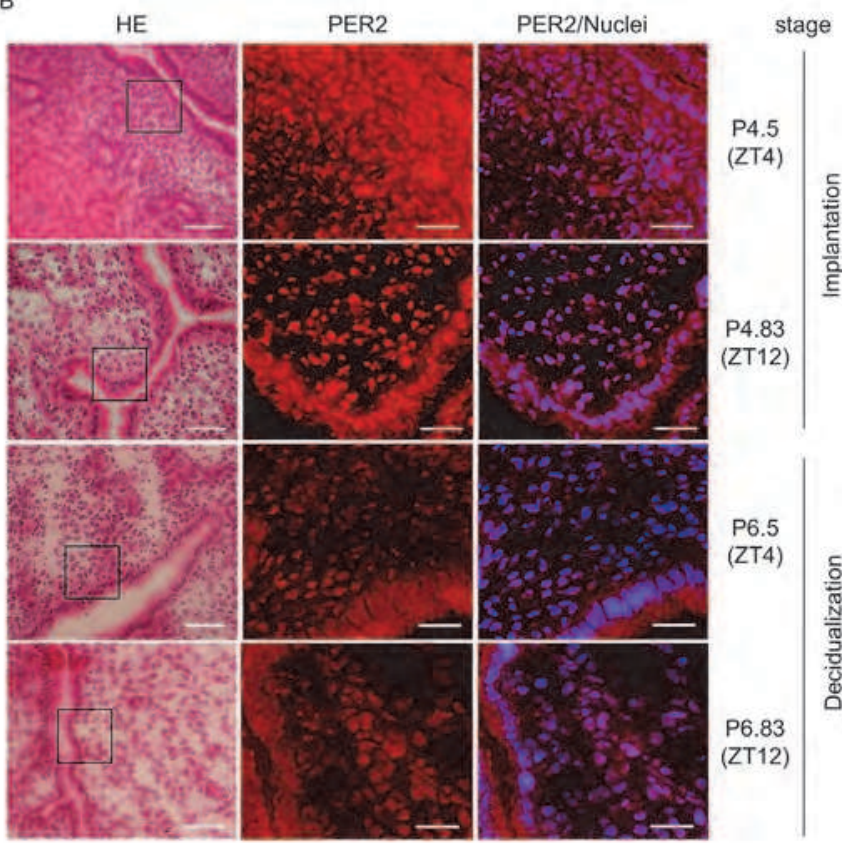

Fig. 7. Circadian rhythm of the PER2 protein and representative photomicrographs of immunofluorescent analyses for PER2 protein in the uteri of pregnant rats during the stages of implantation and decidualization. A, Pregnant rats were killed at 4-h intervals over a daily cycle $(Z T 0,0800 \mathrm{~h})$. Proteins $(30 \mu \mathrm{g})$ prepared from a part of the uterine horns were separated on SDS-PAGE, and analyzed by immunodetection using anti-mPER2 antibody. Data are means \pm SEM from three independent experiments normalized to the values given by $\alpha$-tubulin. Values with different letters are significantly different $(p<0.05)$. Shaded areas, during the night. B, Parts of uterine horns at ZT4 and ZT12 were subjected to fluorescent immunohistochemistry. The square regions shown in HE were magnified from a serial section subjected to immunofluorescent studies of the PER2 protein (red) and Hoechst staining (blue). Scale bars: $150 \mu \mathrm{m}$ (HE), $50 \mu \mathrm{m}$ (PER2, PER2/Nuclei).

dexamethasone and forskolin. Circadian oscillation was generated in these cells, albeit with a continuous decrease of amplitude (Fig. 8). However, the response to forskolin showed a greater decrease from P2.5 to P6.5 than the response to dexamethasone. This suggests that the effect of cAMP signalling on the circadian rhythm of clock genes is weak. Of interest, the oscillatory intensity was low in the stroma cells at day 7, at which these cells undergo decidualization. This suggests that the circadian oscillator is impaired in the stroma cells during decidualization. During the stage of implantation, dramatic changes are observed in the expression of hypoxia-inducible factor $1 \alpha(\mathrm{HIF} 1 \alpha)$ and vascular endothelial growth factor (VEGF), angiogenesis, down-regulation of anti-adhesion proteins, and up-regulation of adhesion proteins. Several of these genes are known to interact with the clock gene transcription factors. BMAL1 can dimerize with HIF1 $\alpha$ and may bind to the hypoxia response elements in the promoters and drive the transcription of target genes (Hogenesch et al., 1998). On the other hand, during the stage of decidualization, the decidual cells 


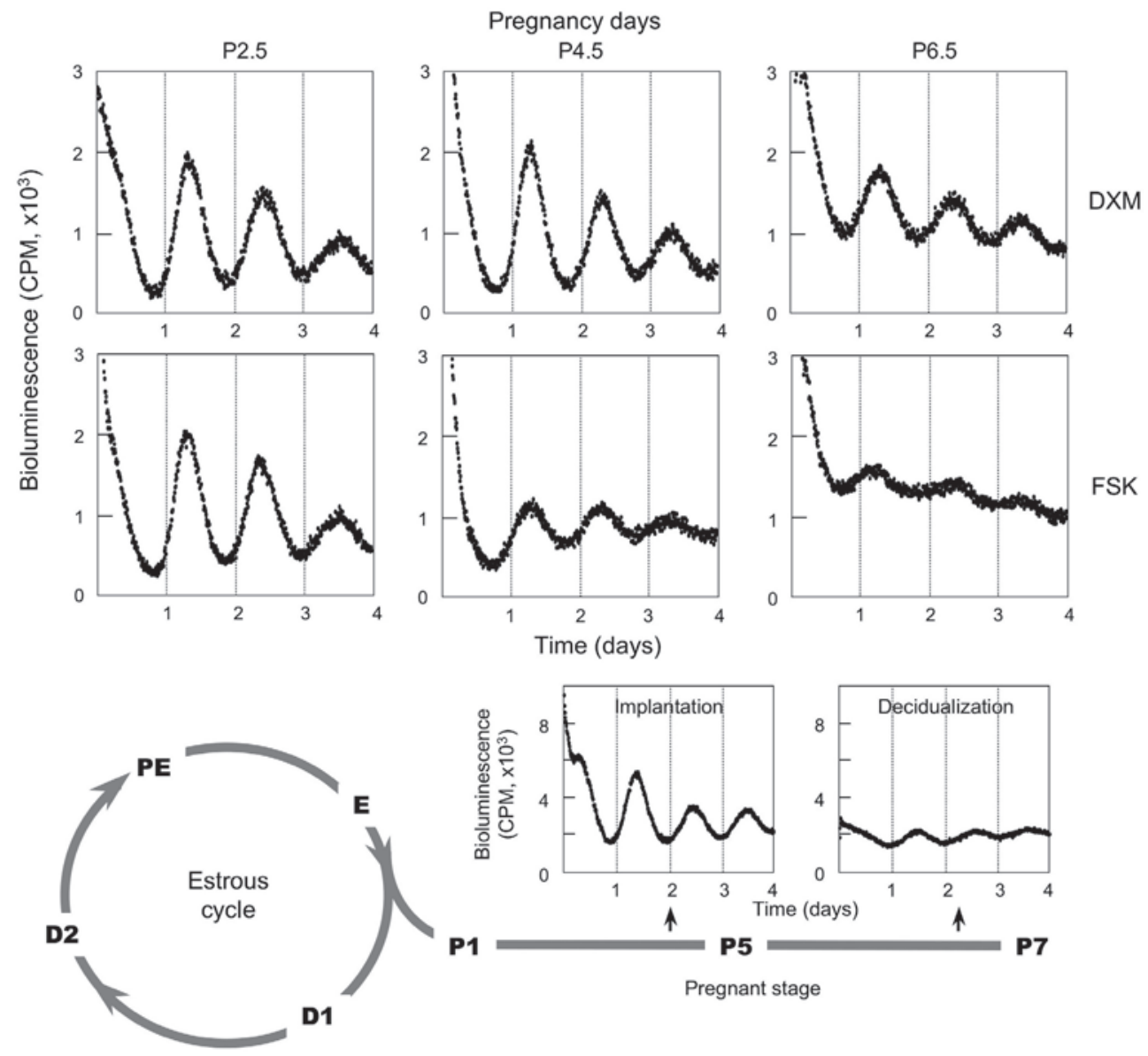

Fig. 8. Profiles of Per2-dLuc oscillation in uterine endometrial stroma cells prepared from pregnant rats at day 2.5 (P2.5), day 4.5 (P4.5) and day 6.5 (P6.5) of gestation. After the stroma cells were cultured for $48 \mathrm{~h}$, they were treated with dexamethasone (DXM) or forskolin (FSK) for $2 \mathrm{~h}$, and then subjected to real-time monitoring of bioluminescence.

express many peptides including desmin, IGF-binding proteins, tumor necrosis factor, and decidual prolactin-related protein. Some of these factors may be controlled under the circadian clockwork. For example, the Vegf gene has at least 7 E-box and E-box-like sites within the -5000 upstream of the transcription start site (NC_005108). Circadian oscillation of Vegf mRNA was observed during the stage of implantation, whereas it was not seen during the stage of decidualization (Fig. 9). In addition, the circadian rhythm of the Vegf mRNA was consistent with that of the Per 2 mRNA (Uchikawa et al., 2011). This suggests a clock regulation of the $V e g f$ gene. Clearly, the circadian oscillator is down-regulated in the uterine endometrial stroma cells during decidualization. This strongly suggested that cellular differentiation in the stroma cells interferes with the circadian clockwork. 

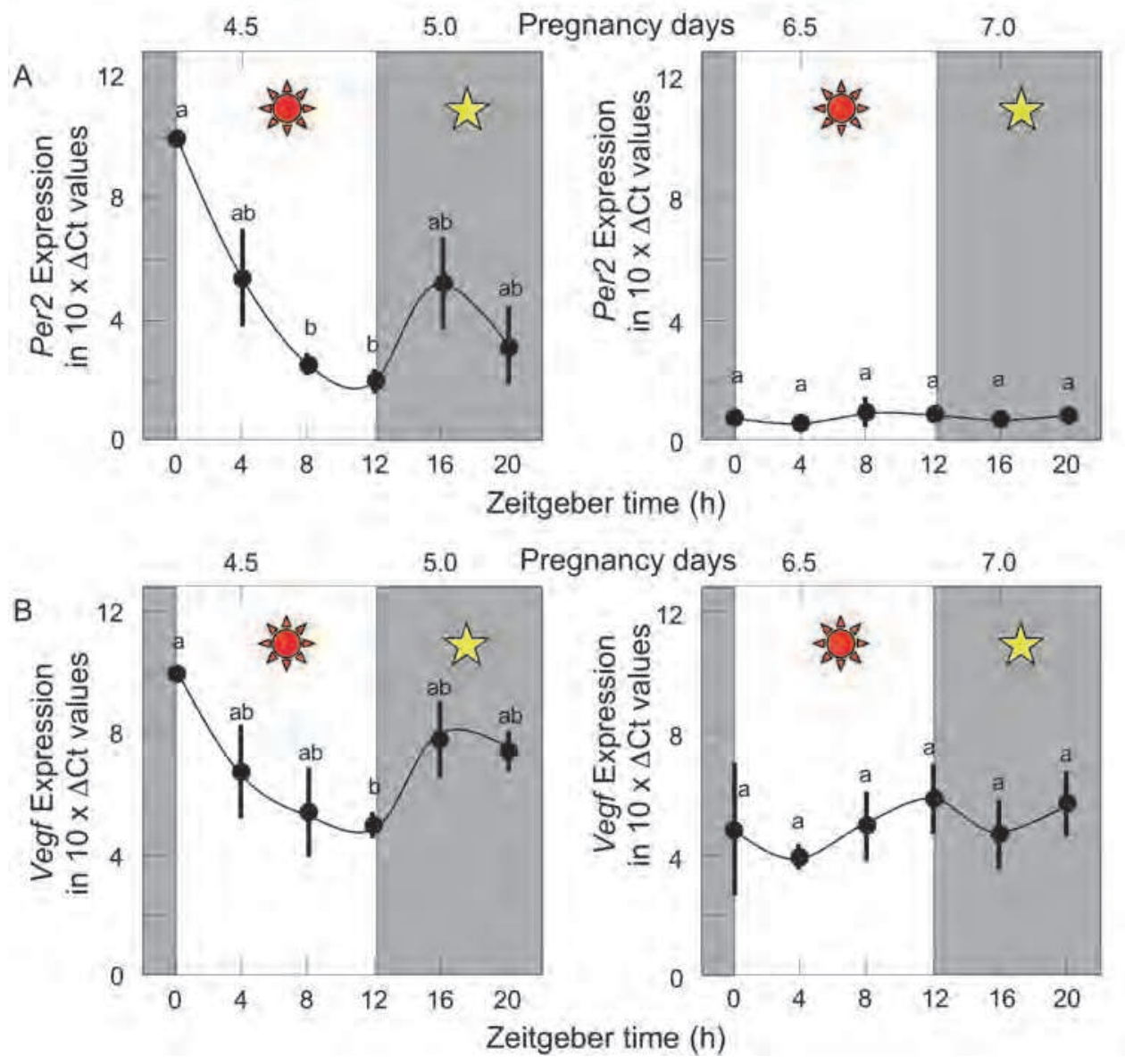

Fig. 9. Circadian rhythms of Per2 and Vegf transcripts in the uterine tissues of pregnant rats during the implantation and decidualization stages. RNA was extracted from a part of uterine horns and reverse transcribed. The resulting cDNA was used for real-time qPCR for Per2 and Vegf mRNAs. (A) Left, Per 2 mRNA expression was significantly altered in the uterine tissues of pregnant rats during implantation (day 4.33-5.16 of gestation). Right, Per2 mRNA expression did not change significantly in the uterine tissues of pregnant rats during decidualization (day $6.33-7.16$ of gestation). (B) Left, Vegf mRNA expression was significantly altered in the uterine tissues of pregnant rats during implantation. Right, Vegf mRNA expression did not significantly change in the uterine tissues of pregnant rats during decidualization. Data are means \pm SEM from three independent experiments normalized to the values given by Gapdh. Values with different letters are significantly different $(p<0.05)$.

\section{Conclusions}

The circadian pacemaker undergoes changes in ovarian and uterine cells during cellular differentiation as follows. Firstly, the circadian pacemaker in ovarian cells is modulated during 
follicular development. Secondly, ovarian steroids promote expression of Per1 and Per2 in uterine endometrial stroma cells. Especially, progesterone may recover the deregulation of the circadian oscillator induced by eCG-produced estradiol. Thirdly, the circadian oscillator is down-regulated in the uterine endometrial stroma cells during decidualization. The alteration of the circadian pacemaker in the ovarian and uterine cells results largely from hormonal inputs such as gonadotropins and ovarian steroids, possibly via the regulatory elements such as the cAMP response element and steroid hormone response element half-sites (Fig. 10). However, cell differentiation may also disrupt the circadian pacemaker.

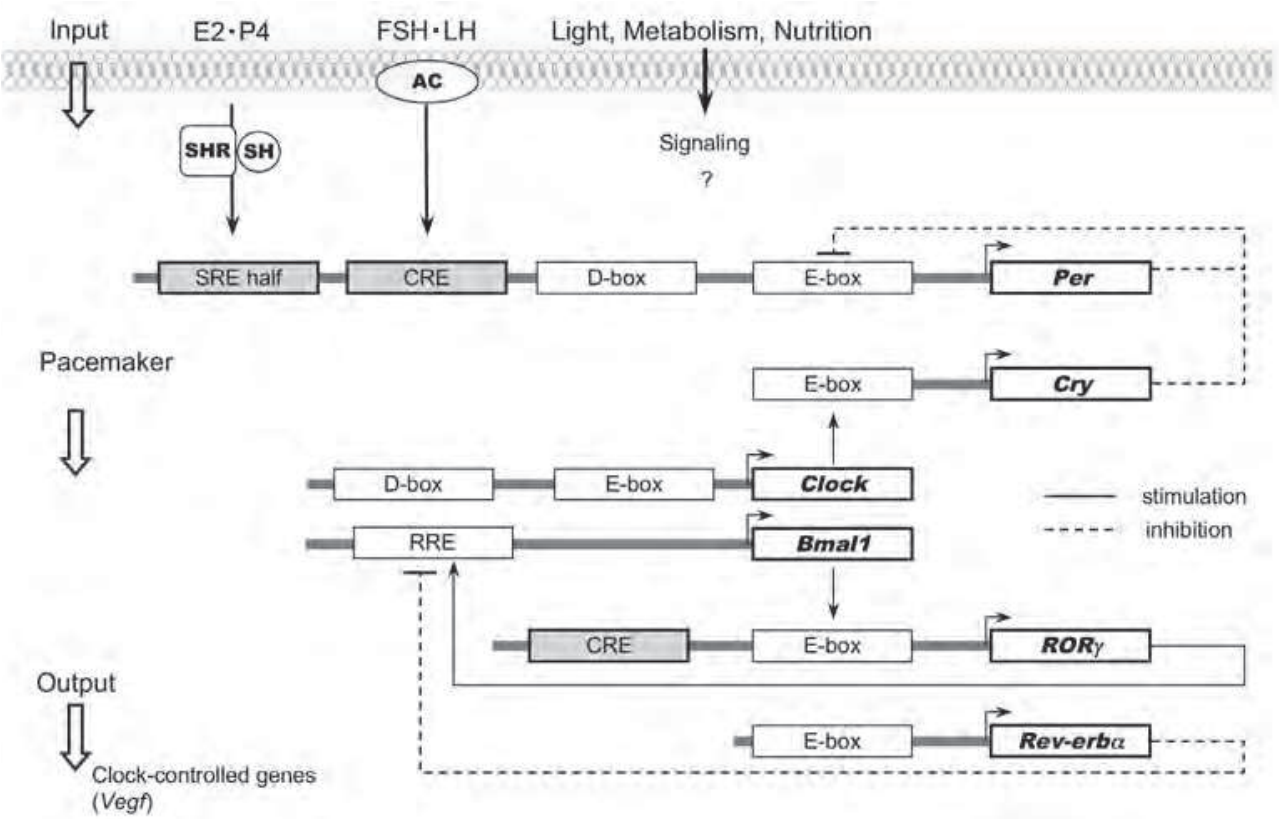

Fig. 10. Hormonal regulation of circadian clock system in cell functions via identified transcriptional and posttranscriptional regulatory processes. The CLOCK-BMAL1 heterodimers bind to the canonical E-box element of clock genes and initiate the transcription activities of these genes. In addition to the E-box and D-box elements, many SHE half and CRE sites are located at the upstream of clock genes. As the input pathway, hormonal and environmental signals are transmitted to the pacemaker. The clock system may contribute to the progress of follicular development, luteinization and luteolysis, and steroid hormone-induced proliferation and differentiation of uterine cells through fluctuating hormones. SH: steroid hormones, AC: adenylate cyclase. 


\section{Acknowledgments}

This research was collaborated with Dr. P-J. He (Emory University, GA, USA), Dr. N. Yamauchi (Kyushu University, Fukuoka, Japan), Dr. Y. Xi (Zhejiang University, Hangzhou, China), Dr. S. Hashimoto (The University of Tokyo, Tokyo, Japan) and Dr. Y. Shigeyoshi (Kinki University School of Medicine, Osaka, Japan). This work was funded by a Grant-inAid for Scientific Research from the Japan Society for the Promotion of Sciences (JSPS; 19658099, 22380152).

\section{References}

Balsalobre, A., Brown, S.A., Marcacci, L., Tronchen, F., Kellendonk, C., Reichardt, H.M., Schutz, G. \& Schibler, U. (2000a). Resetting of circadian time in peripheral tissues by glucocorticoid signalling. Science 289:2344-2347.

Balsalobre, A., Marcacci, L. \& Schibler, U. (2000b). Multiple signaling pathways elicit circadian gene expression in cultured Rat-1 fibroblasts. Curr. Biol. 10:1291-1294.

Beaver, L.M., Rush, B.L., Gvakharia, B.O. \& Giebultowicz, J.M. (2003). Noncircadian regulation and function of clock genes period and timeless in oogenesis of Drosophila melanogaster. J. Biol. Rhythms 18:463-472.

Carson, D.D., Bagchi, I., Dey, S.K., Enders, A.C., Fazleabas, A.T., Lessey, B.A. \& Yoshinaga, K. (2000). Embryo implantation. Dev. Biol. 223:217-237.

Clarke, C.L. \& Sutherland, R.L. (1990). Progestin regulation of cellular proliferation. Endocr. Rev. 11:266-301.

Dey, S.K., Lim, H., Das, S.K., Reese, J., Paria B.C., Daikoku, T. \& Wang, H. (2004). Moecular cues to implantation. Endocr. Rev. 25:341-373.

Dolatshad, H., Campbell, E.A., O’hara, L., Maywood, E.S., Hastings, M.H. \& Johnson, M.H. (2006). Developmental and reproductive performance in circadian mutant mice. Hum. Reprod. 21:68-79.

Duguay, D. \& Cermakian, N. (2009). The crosstalk between physiology and circadian clock proteins. Chronobiol. Int. 26:1479-1513.

Fahrenkrug, J., Georg, B., Hannibal, J., Hindersson, P. \& Gras, S. (2006). Diurnal rhythmicity of the clock genes Per1 and Per2 in the rat ovary. Endocrinology 147:3769-3776.

He, P-J., Hirata, M., Yamauchi, N., Hashimoto, S. \& Hattori, M-A. (2007a). Gonadotropic regulation of circadian clockwork in rat granulosa cells. Mol. Cell. Biochem. 302:111118.

He, P-J., Hirata, M., Yamauchi, N., Hashimoto, S. \& Hattori, M-A. (2007b). The disruption of circadian clockwork in differentiating cells from rat reproductive tissues as identified by in vitro real-time monitoring system. J. Endocrinol. 193:413-420.

He, P-J., Hirata, M., Yamauchi, N. \& Hattori, M-A. (2007c). Up-regulation of Per1 expression by estradiol and progesterone in the rat uterus. J. Endocrinol. 194:511-519.

Hirata, M., He, P-J., Shibuya, N., Uchikawa, M., Yamauchi, N., Hashimoto, S. \& Hattori, MA. (2009). Progesterone, but not estradiol, synchronizes circadian oscillator in the uterus endometrial stroma cells. Mol. Cell. Biochem. 324:31-38. 
Hogenesch, J.B., Gu, Y.Z., Jain, S. \& Bradfield, C.A. (1998). The basic-helix-loop-helix-PAS orphan MOP3 forms transcriptionally active complexes with circadian and hypoxia factors. Proc. Natl. Acad. Sci. USA 95:5474-5479.

Horard, B., Rayet, B., Triqueneaux, G., Laudet, V., Delaunay, F. \& Vanacker, J.M. (2004). Expression of the orphan nuclear receptor ERR $\alpha$ is under circadian regulation in estrogen-responsive tissues. J. Mol. Endocrinol. 33:87-97.

Johnson, M.H., Lim, A., Fernando, D. \& Day, M.L. (2002). Circadian clockwork genes are expressed in the reproductive tract and conceptus of the early pregnant mouse. Reprod. Biomed. Online 4:140-145.

Karman, B.N. \& Tischkau, S.A. (2006). Circadian clock gene expression in the ovary: effects of luteinizing hormone. Biol. Reprod. 75:624-632.

Nakamura, T.J., Moriya, T., Inoue, S., Shimazoe, T., Watanabe, S., Ebihara, S. \& Shinohara, T. (2005). Estrogen differentially regulates expression of Per1 and Per2 genes between central and peripheral clocks and between reproductive and nonreproductive tissues in female rats. J. Neurosci. Res. 82:622-630.

Nakao, N., Yasuo, S., Nishimura, A., Yamamura, T., Watanabe, T., Anraku, T., Okano, T., Fukada, Y., Sharp. P.J., Ebihara, S. \& Yoshimura, T. (2007). Circadian clock gene regulation of steroidogenic acute regulatory protein gene expression in preovulatory ovarian follicles. Endocrinology 148:3031-3038.

Nephew, K.P., Long, X., Osborne, E., Burke, K.A., Ahluwalia, A. \& Bigsby, R.M. (2000). Effect of estradiol on estrogen receptor expression in rat uterine cell types. Biol. Reprod. 62:168-177.

Perrin, J.S., Segall, L.A., Harbour, V.L., Woodside, B. \& Amir, S. (2006). The expression of the clock protein PER2 in the limbic forebrain is modulated by the estrous cycle. Proc. Natl. Acad. Sci. USA 103:5591-5596.

Reppert, S.M. \& Weaver, D.R. (2001). Molecular analysis of mammalian circadian rhythms. Annu. Rev. Physiol. 63:647-676.

Schibler, U. \& Sassone-Corsi, P. (2002). A web of circadian pacemakers. Cell 111:919-922.

Sellix, M.T. \& Menaker, M. (2010), Circadian clocks in the ovary. Trends Endocrinol. Metab. 21:628-636.

Tilly, J.L., Billig, H., Kowalski, K.I. \& Hsueh, A.J. (1992). Epidermal growth factor and basic fibroblast growth factor suppress the spontaneous onset of apoptosis in cultured rat ovarian granulosa cells and follicles by a tyrosine kinase-dependent mechanism. Mol. Endocrinol. 6:1942-1950.

Travnickova-Bendova, Z., Cermakian, N., Reppert, S.M. \& Sassone-Corsi, P. (2002). Biomodal regulation of mPeriod promoters by CREB-dependent signaling and CLOCK/BMAL1 activity. Proc. Natl. Acad. Sci. USA 99:7728-7733.

Uchikawa, M., Kawamura, M., Yamauchi, N. \& Hattori, M-A. (2011). Down regulation of circadian clock gene Period 2 in uterine endometrial stromal cells of pregnant rats during decidualization. Chronobiol. Int. 28:1-9.

Ueda, H.R., Chen, W., Adachi, A., Wakamatsu, H., Hayashi, S., Takasugi, T., Nagano, M., Nakahara, K., Suzuki, Y., Sugano, S., Iino, M., Shigeyoshi, Y., Iino, M. \& Hashimoto, S. (2002). A transcription factor response element for gene expression during circadian night. Nature 418:534-539. 
Ueda, H.R., Hayashi, S., Chen, W., Sano, M., Machida, M., Shigeyoshi, Y., Iino, M. \& Hashimoto, S. (2005). System-level identification of transcriptional circuits underlying mammalian circadian clocks. Nat. Genet. 37:187-192.

Yamamoto, T., Nakahata, Y., Soma, H., Akashi, M., Mamine, T. \& Takumi, T. (2004). Transcriptional oscillation of canonical clock genes in mouse peripheral tissues. BMC Mol. Biol. 5:18. 


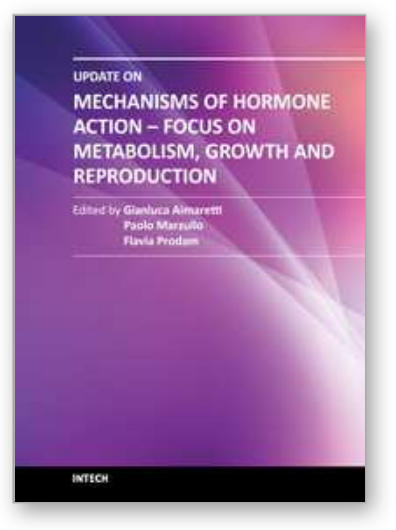

\section{Update on Mechanisms of Hormone Action - Focus on Metabolism, Growth and Reproduction}

Edited by Prof. Gianluca Aimaretti

ISBN 978-953-307-341-5

Hard cover, 470 pages

Publisher InTech

Published online 26, October, 2011

Published in print edition October, 2011

The purpose of the present volume is to focus on more recent aspects of the complex regulation of hormonal action, in particular in 3 different hot fields: metabolism, growth and reproduction. Modern approaches to the physiology and pathology of endocrine glands are based on cellular and molecular investigation of genes, peptide, hormones, protein cascade at different levels. In all of the chapters in the book all, or at least some, of these aspects are described in order to increase the endocrine knowledge.

\section{How to reference}

In order to correctly reference this scholarly work, feel free to copy and paste the following:

Masa-aki Hattori (2011). Hormonal Regulation of Circadian Pacemaker in Ovary and Uterus, Update on Mechanisms of Hormone Action - Focus on Metabolism, Growth and Reproduction, Prof. Gianluca Aimaretti (Ed.), ISBN: 978-953-307-341-5, InTech, Available from: http://www.intechopen.com/books/update-onmechanisms-of-hormone-action-focus-on-metabolism-growth-and-reproduction/hormonal-regulation-ofcircadian-pacemaker-in-ovary-and-uterus

\section{INTECH}

open science | open minds

\section{InTech Europe}

University Campus STeP Ri

Slavka Krautzeka 83/A

51000 Rijeka, Croatia

Phone: +385 (51) 770447

Fax: +385 (51) 686166

www.intechopen.com

\section{InTech China}

Unit 405, Office Block, Hotel Equatorial Shanghai

No.65, Yan An Road (West), Shanghai, 200040, China

中国上海市延安西路65号上海国际贵都大饭店办公楼405单元

Phone: +86-21-62489820

Fax: $+86-21-62489821$ 
(C) 2011 The Author(s). Licensee IntechOpen. This is an open access article distributed under the terms of the Creative Commons Attribution 3.0 License, which permits unrestricted use, distribution, and reproduction in any medium, provided the original work is properly cited. 